\title{
Design and experimental test of a low costweather buoy
}

\author{
Vincenzo Franzitta; Marco Trapanese, Carlo Giaconia, Paolo Ferrara, Alessia Viola \\ Dipartimento di Energia, Ing. Informazione, Mod. Matematici \\ Palermo University \\ Palermo, Italy \\ franzitta@dream.unipa.it \\ marco.trapanese@unipa.it \\ carlo.giaconia@unipa.it \\ paolo.ferrara@unipa.it \\ alessia.viola@uniap.it
}

\begin{abstract}
The importance of prevention plans based on realistic inundation scenarios was dramatically highlighted by the Indian Ocean Tsunami of 26 December 2004. But also in the Mediterranean, sea storms basin are a quite common event especially during winter months. These scenarios are generally based on numerical models of tsunami wave propagation that can become more realistic and effective when calibrated with the distribution of true data acquired by special weather buoy. In this paper we present the result of an experimental weather buoy built by DEIM of University of Palermo, that is characterized by small cost and big versatility.
\end{abstract}

Keywords—sea wave; software; buoy; marine techonologie;

\section{INTRODUCTION}

Weather buoys are instruments which collect weather and ocean data within the world's oceans. Moored buoys have been in used since 1951, while drifting buoys have been used since 1979. Moored buoys are connected with the ocean bottom using either chains, nylon, or buoyant polypropylene. With the decline of the weather ship, they have taken a more primary role in measuring conditions over the open seas since the 1970s. During the 1980s and 1990s, a network of buoys in the central and eastern tropical Pacific ocean helped study the El Niño-Southern Oscillation.[1]

Drifting buoys are the dominant form of weather buoy in sheer number, with 1250 located worldwide. Wind data from buoys has smaller error than that from ships. There are differences in the values of sea surface temperature measurements between the two platforms as well, relating to the depth of the measurement and whether or not the water is heated by the ship which measures the quantity.[2-3]

Weather buoys, like other types of weather stations, measure parameters such as air temperature above the ocean surface, windspeed (steady and gusting),barometric pressure, and wind direction.[4-5] Since they lie in oceans and lakes, they also measure water temperature, wave height, and dominant wave period. Raw data is processed and can be logged on board the buoy and then transmitted via radio, cellular, or satellite communications to meteorological centers for use in weather forecasting and climate study. Both moored buoys and drifting buoys (drifting in the open ocean currents) are used. Fixed buoys measure the water temperature at a depth of 3 metres $(9.8 \mathrm{ft})$. Many different drifting buoys exist around the world that vary in design and the location of reliable temperature sensors varies. These measurements are beamed to satellites for automated and immediate data distribution. Other than their use as a source of meteorological data, their data is used within research programs, emergency response to chemical spills, legal proceedings, and engineering design. Moored weather buoys can also act as a navigational aid, like other types of buoys [6-7].

\section{CASE STUDY}

The DEIM buoy system suitable either for shallow water or lagoons areas or no sheltered deeper sea sites. This buoy have important advantages and features, as:

- On line aerial data transmission (telephone line)

- Easy assembling and installation

- Low cost

- Solar panels maintenance free for the power supply.

In the following Fig. 1 we can see the dimension of the DEIM weather buoy". 

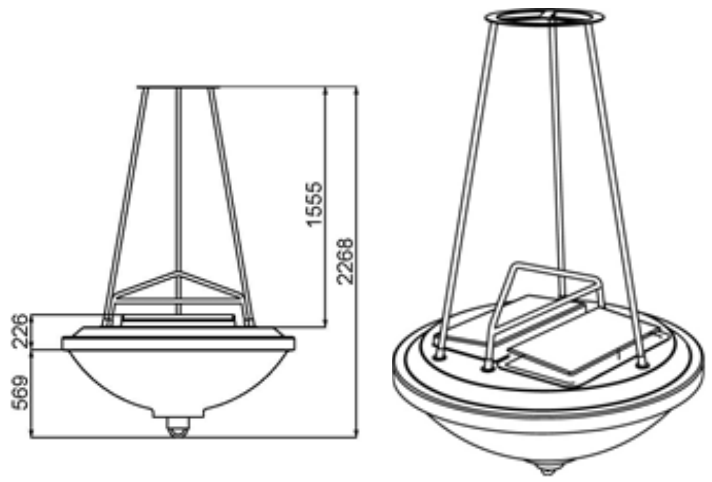

Fig. 1. Layout of weather buoy

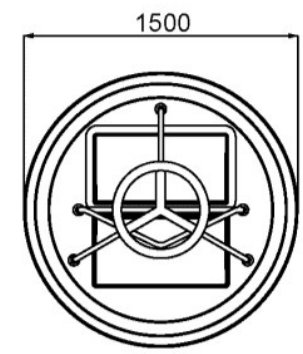

Fig. 2. Top view of buoy

The heart of the system consists of a RISC microcontroller Microchip PIC 18F2620 with an internal crystal oscillator with a clock frequency of $40 \mathrm{MHz}$ that allows programs to run at a speed of no less than 10 MIPS. The microcontroller supervises all the operations required for operating the device data acquisition, in the monitoring and remote management [8-9].

The digital multiplexer allows you to share serial port of the PIC module with the Telit GSM / GPRS / GPS and with the removable mass storage, managed by the micro SD card reader, which is carried on the back-up your data.A suitable network allows to adapt the logic levels of the PIC to those of the Telit module and the reader $\mu$ Drive.

The figure 3 shows the block diagram of the geo-referenced acquisition and transmission dates mounted inside the buoy.

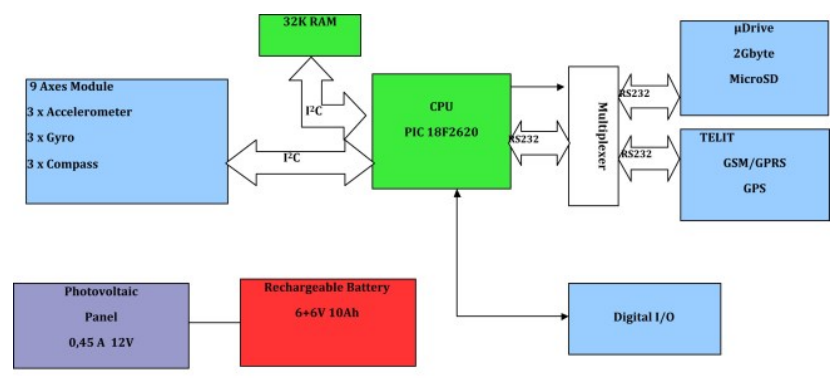

Fig. 3. Geo-referenced system
The main sensor is represented by a tab SMD assembling on board a triaxial accelerometer, a triaxial gyroscope and a compass triaxial; connection to the microcomputer is bidirectional $\mathrm{I} 2 \mathrm{C}$. The resolution of the sensors of the module to 9 axes is as follows:

- Compass 12-bit

- Accelerometer 13-bit

- Gyroscope 16-bit

For a total of 41 bits each of the axes $(X, Y, Z)$ will therefore have 123 bits for each sample (16 8-bit byte). Using the maximum possible speed sampling is possible to have an acquisition every $0.1 \mathrm{sec}$. To manage this flow of information is required to adopt a compression technique.

The digital inputs mounted are contacts On / Off to inform the system of any openings or openings of the buoy;

Taking advantage of the multi-channel ADC converter of the microcontroller can monitor the charge level of the battery, the voltage supplied by the solar panel and the charging current of the battery. Data is stored on a microSD card with a maximum capacity of 2 Gigabyte allowed by the card reader ( $\mu$ Drive) [10]. Considering that the data can be stored using a compression algorithm such as that described later, it is possible to estimate a back-up of over 5 months of data.The Telit module with phone SIM card, manages the connection to the telephone network GSM / GPRS network and then to the Internet Web. On board the same module is also mounted a GPS receiver to 12 satellites[11].

The GPS module also allows you to capture the exact values of date and time, eliminating the need to mount on a board RTC (Real Time Clock) for the timing of activities related to the operation of the module;

The $32 \mathrm{~K}$ RAM with $\mathrm{I} 2 \mathrm{C}$ output is expected to function as a buffer to store the sampled data prior to compression, storing them on the microSD card and the final submission to the Internet Server. Only after the ackowledgement receiving valid data sent in response from the remote server RAM will be erased and rewritten.

A backup battery and a solar panel to complete the system for what concerns the power of the module. Alternatively, they can be studied Power Systems-pack high capacity batteries to be mounted outside of the buoy for easy replacement. The module is powered by a switching regulator that provides $4.2 \mathrm{~V}$ voltage necessary for the proper functioning of the Telit module and the remaining devices[12].

A careful analysis of the running times of various devices and run-time management program ensures that you can easily sampled 10 times per second for the 9 parameters from the acceleration sensor ( 3 for accelerations, 3 for position and 3 for gyroscopic the magnetic field), compress them within the static RAM $32 \mathrm{~K}$ and generate data packets that will be sent to the remote server using the Telit module[1-3]. The machine time remaining is more than sufficient to ensure also the other auxiliary services such as the position control, alarm management and control of the voltages. 
As mentioned above, the acquired data are sent via the GSM / GPRS module directly to an Internet server through a PHP script residing on the server. With the POST method sends the entire compressed package. The PHP code will unpack the received data and insert them into a MySQL database. An HTML page, to which access will be password protected, it will allow for consultation or downloading on the part of authorized users.[4]

\section{ACQUiSITION DATA SYSTEM}

Given the inertia of the system, the acquired data should vary relatively slowly, so it is conceivable that the difference between a sample value and the next is quite small. Determined the maximum variation for each type of data, it is possible to adopt a compression system simple, effective and which requires few resources of calculation by the CPU.

A data packet can be formed by the 9 initial values of the relative sensors ( 123 bit) followed by $4 / 5 / 6$... bits per channel that indicate the change compared to the previous value.

For example, suppose for a minute of uncompressed samples are needed 73800 bits or 9225 bytes. The following table shows the possible compression with different resolutions.[6].

The number of bits required can be determined experimentally by analyzing a data stream is not compressed.

TABLE I VALUES CALCULATED FOR A MINUTE SAMPLING.

\begin{tabular}{|c|c|c|c|c|}
\hline \multicolumn{5}{|c|}{ Data of system } \\
\hline Max Range & Coding Bit & Bit area & $\begin{array}{c}\text { Approssima } \\
\text { tive byte } \\
\text { area }\end{array}$ & $\begin{array}{c}\text { Compressio } \\
\text { n } \\
\text { percentage }\end{array}$ \\
\hline $\pm 8(-8 . .+7)$ & 4 bit & 21687 bit & 2711 & $29,38 \%$ \\
\hline $\pm 16(-16 .++15)$ & 5 bit & 27078 bit & 3385 & $36,69 \%$ \\
\hline $\pm 32(-32 .+31)$ & 6 bit & 32469 bit & 4059 & $43,99 \%$ \\
\hline $\pm 64(-64 \ldots+63)$ & 7 bit & 37860 bit & 4733 & $51,30 \%$ \\
\hline $\begin{array}{c} \pm 128(-128 . . \\
+127)\end{array}$ & 8 bit & 43251 bit & 5407 & $58,60 \%$ \\
\hline- & $\begin{array}{c}\text { No } \\
\text { encryption }\end{array}$ & 73800 bit & 9225 & $0,00 \%$ \\
\hline
\end{tabular}

A reduction of the amount of data means more space available in the memory for the data, smaller packets and less transmission time thus saving energy stored in batteries

\section{FUNCTION'S SYSTEM}

In addition to the simple task of acquisition, storage and transmission of data, the system must also be able to ensure the following functions:

-Automatic reset due to errors or unexpected random block system (watchdog function);
-Restore the system configuration (time, location, historical data acquired) after reset (using scratchpad RAM);

-Check the connection of GSM and GPS data before sending;

-Check validity of data from the mean value of previous data;

-Control successful reception of the data (acknowledgment) from the remote system;

-Immediate notice of tampering or opening of the buoy;

-Immediate notice of the emergency situation in case the buoy moves significantly from the point of installation;

-Low battery alert;

-Contract failure of the solar panel;

-Setting up a remote time of sending data;

-Setting the remote execution of some basic parameters.

These functions are carried out directly by the software resident on board. Other alarm functions or management of particular events may be entrusted to the Internet[8] Server such as sending specific alerts in case the buoy does not transmit more for a certain period. Messages can be sent via email by the system itself or from the Internet Server and, if necessary, for critical alarms can be sent a text message to a predefined number.
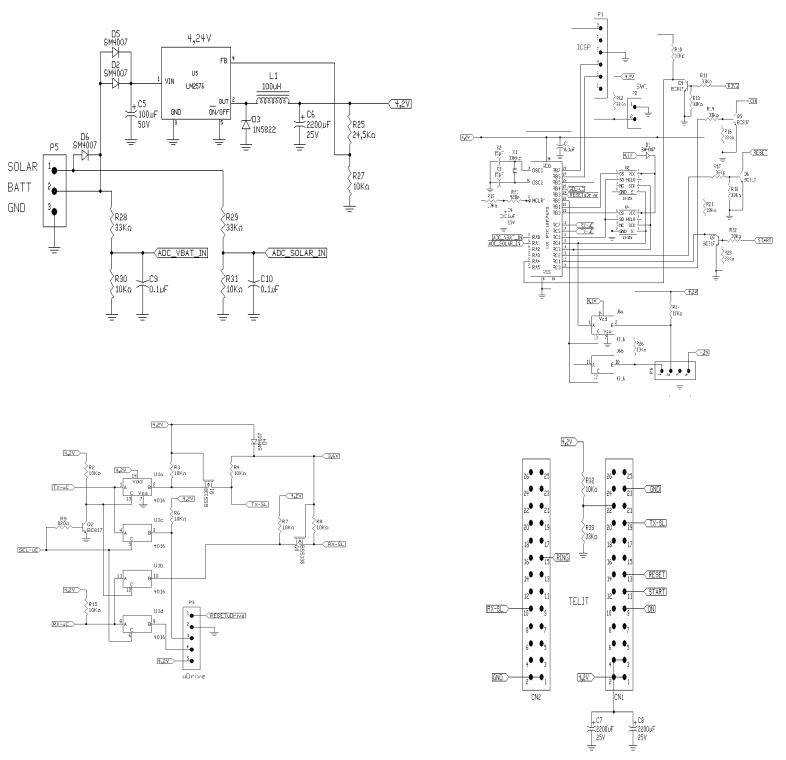

Fig. 4. Electric schemes of thecomponents 


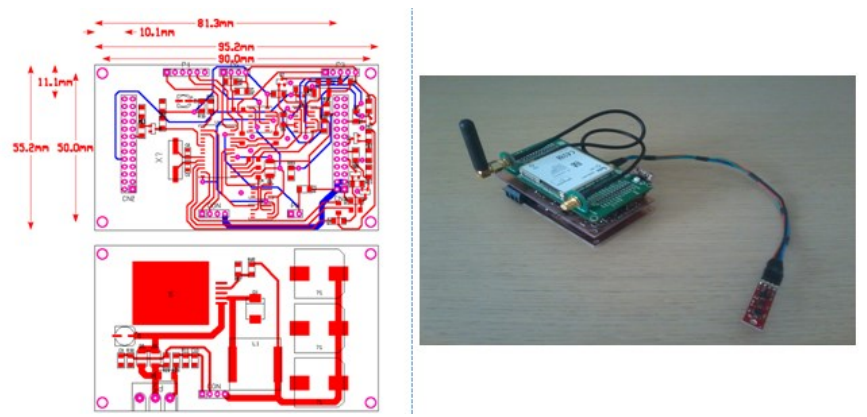

Fig. 5. PCB (Printed Circuit Board) and Module with sensor board

\section{OUTPUT SYSTEM DATA}

The motion sensor ( 9 Axes Module) that includes a triaxial accelerometer, a gyroscope and a compass triaxial triaxial was tested together with the data transmission system to check the possibility of carrying out a preprocessing of data aboard the buoy and limit the number of bytes to send.

In particular, it is addressed the problem of filtration of signals acquired through the development of software that implements a Kalman filter, which, as is known, is an efficient recursive algorithm which evaluates the state of a dynamic system from a series of measures subject to noise.

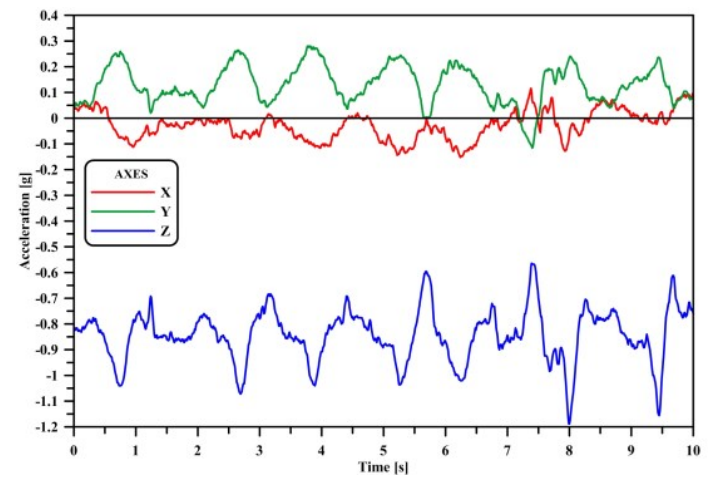

Fig. 6. Example of transmission of filtered data in horizontal motion

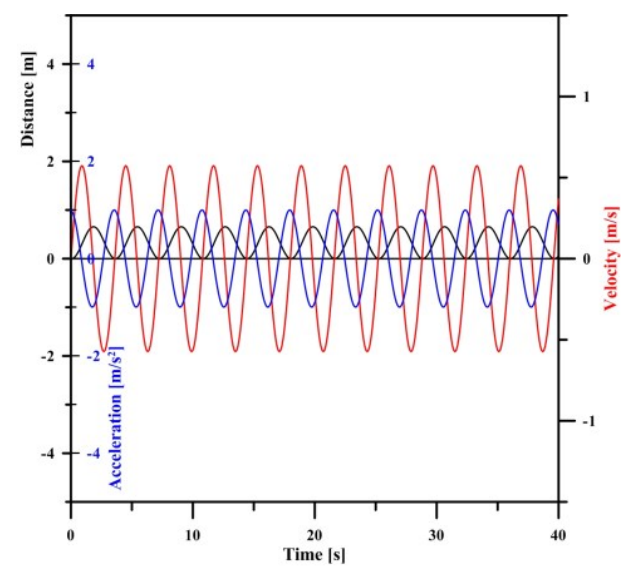

Fig. 7. Example of vertical motion

Figure 6 shows an example of transmission of filtered data during a test of displacement in the horizontal of the sensor subject to slight shifts in the vertical direction. Note the presence of constant vertical component directed downwards and equal to $1 \mathrm{~g}$. The acquisition interval is 0.01 seconds, equal to 100 samples / second

Figure 7 shows an example of vertical motion more energetic, associated with a rotation of the sensor in the horizontal plane. It's shows the excellent sensitivity of the module and the effectiveness of the filtering carried out by software.

Also in this example, the acquisition interval was of 0.01 seconds.

The acceleration data may be further processed and used to calculate the displacements of the module. In figure 8 is shown a test carried out by placing the module on an object in vibration, free to move on the horizontal plane.

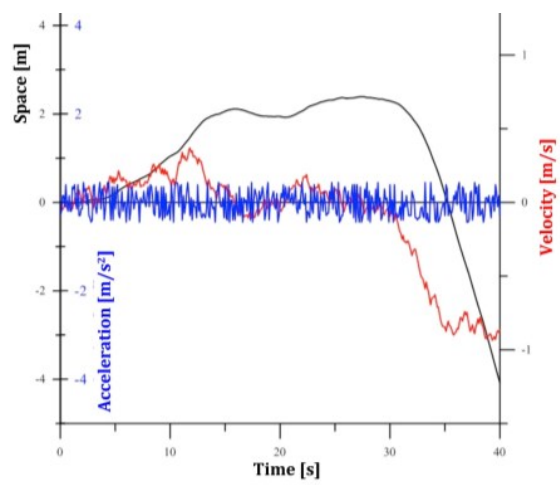

Fig. 8. Example of test in vibration motion

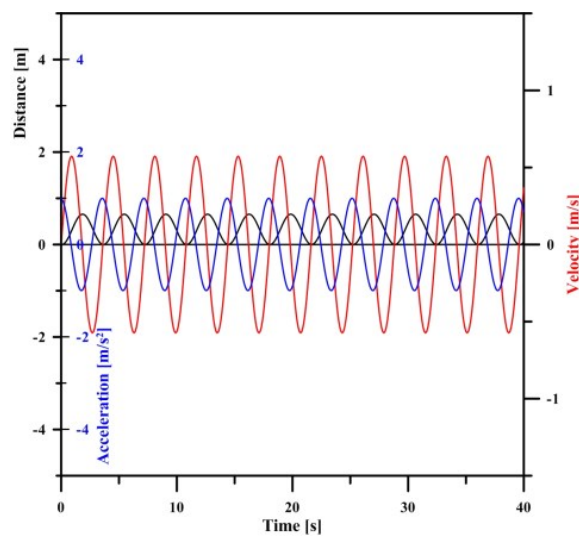

Fig. 9. Example of accuracy of the reconstruction software

Finally figure 9 shows the accuracy of the reconstruction software of the displacement from dummy data of vertical acceleration of the sinusoidal type.

\section{CONCLUSIONS}

.In this paper we present the result of an experimental weather buoy built by DEIM of University of Palermo, that is characterized by small cost and big versatility. This buoy can detects, records and sends all the important parameters of the water column. Its dimensions and the materials used allows to manufacture this device very easily at very low cost. 


\section{ACKNOWLEDGMENT}

This work was funded The font listed was not embedded by Ministero dell'Ambiente e del Mare through IMPETUS project.

\section{REFERENCES}

[1] Bonanno A., Franzitta V., Muzio F.P., Trapanese M., "A multiphysics approach to the design of a seawave energy conversion system", Proceedings of ICSET, Singapore, ,p.p. 665-668,art. no. 4747090, 2008.

[2] Franzitta V., Rizzo G., "Renewable energy sources: A mediterranean perspective", Proceedings ICBEE 2010-2nd International Conference on Chemical, Biological and Environmental Engineering, , p.48-51, art. no. 5652332 (2010).

[3] Di Dio V., Franzitta V., Muzio F., Scaccianoce G., Trapanese M., "The use of sea waves for generation of electrical energy and hydrogen". MTS/IEEE Biloxi - Marine Technology for Our Future: Global and Local Challenges, OCEANS, 2009, art. no. 5422319.

[4] Sorrentino G., Scaccianoce, G., Morale, M., Franzitta, V., "The importance of reliable climatic data in the energy evaluation", Energy Volume 48, Issue 1, pp74-79, December 2012.

[5] Trapanese M., Viola A., Franzitta V. , "Description of hysteresis of nickel metal hybride battery". IECON 2012, 38th Annual Conference on IEEE Industrial Electronics Society, Montreal, Canada, pp. 967-970.

[6] Franzitta V., Viola A., Trapanese M., "Description of hysteresis in Lithium battery by classical Preisach model", Advanced Materials Research Vols. 622-623, pp 1099-1103, 2013.

[7] Ciulla G., Franzitta V., Lo Brano V., Viola A., Trapanese M., "Mini Wind Plant to Power Telecommunication Systems: a Case Study in Sicily", Advanced Materials Research Vols. 622-623 pp 1078-1083, 2013.

[8] Trapanese M., "A model of a linear synchronous motor based on distribution theory", J App Phys, vol.111 ,Article number07E731, 1 April 2012.

[9] Trapanese M, "Noise enhanced stability in magnetic systems", J. App. PhysVolume 105, Issue 7, Article number 07D313, 2009.

[10] Cirrincione M., Miceli R., Galluzzo G.R., M. Trapanese,” Preisach function identification by neural networks", IEEE Transactions on Magnetics Volume 38, Issue 5 I,pp 2421-2423, 2002.

[11] Trapanese M.; Franzitta V., Viola A. "The Jiles Atherton Model for Description Of Hysteresis in Lithium Battery" Conference Proceedings - IEEE Applied Power Electronics Conference and Exposition - APEC 2013- Long Beach,(CA), March 2013-978-1-4673-4355-8, pp 27732775.

[12] Beccali, M., Adhikari, R., Butera, F., Franzitta, V. - "Update on desiccant wheel model" International Journal of Energy Research 28 (12) , pp. 1043-1049 